\title{
Perceived Stress and Happiness in College Students : On the Mediating Effects of Optimism and Flow
}

\author{
Kyoungmi $\mathrm{Kim}^{1}$ )
}

\begin{abstract}
This study investigated the mediating role of optimism and flow in the relationship between perceived stress and subjective happiness in college students. 480 college students were used for analysis. Regression, SPSS Macros, and bootstrapping methods were applied to verify the dual mediation effects. The results follows. First, the more stress perceived, the less happy they were. Second, the higher the optimism and flow among college students, the higher the happiness. Third, the perceived stress of university students indirectly influences happiness through double mediating of optimism and flow. These results suggest the need for a positive mediation program to improve happiness through flow to promote college students' optimism and flow. Finally, we discussed the significance of this study and suggestions for further study.
\end{abstract}

Keywords : Perceived Stress, Subjective Happiness, Optimism, Flow

\section{Introduction}

The period at college is an crucial time of transition from adolescents to adults and is also important in establishing values and planing the future. However, Korean students enter university without establishing their own identity and don't get proper help or training to find it. While they can not escape the high school students' mentality psychologically, their family members and society require them to be autonomous and active[1]. Under these circumstances, college students would be vulnerable to stress symptoms due to the pressure to perform well in exams, employment, interpersonal relations, money problems, independence and identity.

The Comprehensive Survey of Children and Adolescents in 2017 showed that 61 percent of teenagers aged 19 to 24 have experienced stress in their daily lives from time to time. $0.2 \%$ and $1 \%$ respondents said that they were sick for two consecutive weeks or felt depressed occasionally or frequently during a recent year. These results could be a barometer for college students' stress. A Comprehensive Survey on the Mental Health of College Students conducted

Received(October 18, 2018), Review Result(1st: November 5, 2018, 2nd: December 6, 2018), Accepted(December 10, 2018)

1) (Professor) 48520 Dept, Counseling Psychology, Tongmyong Univ., 428 Sinseon-ro, Nam-gu, Busn, Republic of Korea

email: kmkim@tu.ac.kr 
by the Counseling Council of college Student (CCUS) in 2017 showed that $9.7 \%$ of them were found to have been in a depressed status urgently necessary for counseling and psychotherapy. This statistics revealed that it was urgent to pay attention to their stress in an active way and offer stress management programs.

Stress means specific relations between an individual and the environment threatening the welling of an individual in relation to personal resources between a person and the environment[2]. Stress symptoms cause not only psychophysiologic disorders such as headache, fatigue and insomnia but also depression as well as anxiety. Previous studies showed that perceived stress resulted in depression and low subjective happiness[3][4].

However, people under stress don't always experience depression or low levels of happiness. Even though people perceive the same levels of stress, their symptoms are different based on psychological inner characters[5]. When college students are in the same stressful or difficult situations, how to cope with them or adapt to them would be different from individual to individual. So it is necessary to consider another factors explaining the relations between stress and happiness[6]. For example, Lazarus and Folkman suggested a stress-appraisal-coping theory[7], insisting that stress was developed when an individual was endangered and there were no resources to overcome. They also insisted that how to deal with stress could lead to different results. In particular, with the rise of positive psychology, people have paid attention to the positive characteristics that help overcome stress and act as a buffer. An advanced study said that it was important not only to get rid of vulnerable characters or change dysfunctional cognition but also to develop individual's positive resources. This could soften the issues and enhance psychological well-being[8]. This study is to identify the mediating effects of optimism and flow which serve as buffers where stress has an effect on happiness among the young population.

Optimism is an important mental attitude to look on the more favorable side of events for the future[9]. Optimistic people are confident about the future or the success of something and are active in achieving their goals. These positive dispositions help people make an effort to get the result by not giving up in spite of adversity. So optimism is a strong indicator of depression[3][10] and has been studied as an important variable in the expectation of psychological well-being[10][11]. For example, a longitudinal study among college students conducted by Choi Jongan indicated that optimism was a predisposing factor of happiness, The research by Lee Minjeong and Choi Jina(2013) showed that optimism positively predicted[12] psychological well-being among office employees. Furthermore, studies demonstrated that optimism played the mediating[3] or adjusting role[13] between stress and depression among 
teenagers.

Optimistic people are more likely to experience flow in an effort for positive expectations. Flow is the conscious and mental states of being completely immersed in an activity or a work[14]. This full involvement is related to not only mind and health but also a person's capacity. During flow, people experienced deep enjoyment and competency as well as happiness[15]. LeFervre(1988) said that more fully immersed people felt more satisfaction[16]. Wells(1988) insisted that a working mom's deep commitment to a workplace made her feel a better person[17]. A study in Korea indicated that teachers in a total involvement experienced more happiness[18]. These indicate that optimism and flow may serve as important variables predicting happiness.

In addition to that, a precedent study on optimism, flow and happiness showed that optimistic teachers were more likely to experience high levels of flow with teaching and feel happier[18]. An advanced study by Cho Hanik(2013) indicated that high levels of optimism toward school learning among high school students increased flow and then improved academic performances[19]. And optimism with learning had a positive effect on academic performances with the mediating effect of learning flow.

Against this backdrop, stress would affect college students' happiness with the mediating effects of optimism and flow. So this study is to identify the mediating effects of optimism and flow where stress has an effect on their happiness. This would help provide basic data to enhance their mental health and then seek practical ways.

To this end, this research established study questions as follows: Firstly, which relations do perceived stress, optimism, flow and subjective happiness have among college students? Secondly, what kind of mediating roles do optimism and flow have in the relationship between perceived stress and subjective happiness?

To deal with study questions, the study model was presented as follows[Fig. 1].

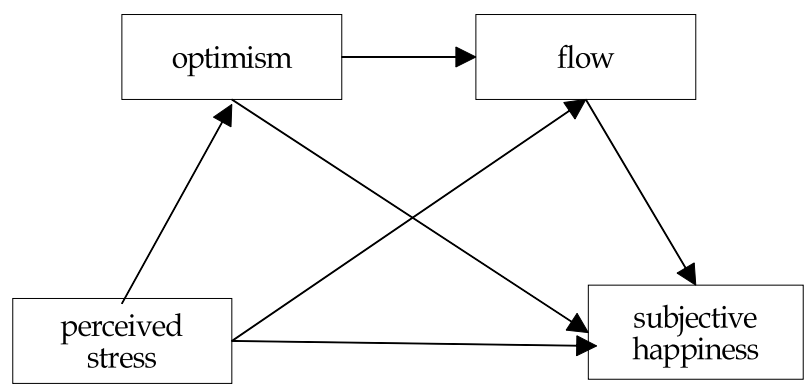

[Fig. 1] Research Model 


\section{Study Method}

\subsection{Participants}

A researcher conducted a survey among 480 college students in Seoul, Chungcheongnam-do, Jeollabuk-do and Gyeongsangnam-do. The average age was 22.86 ( $\mathrm{SD}=1.95)$. A total of 473 people participated in the study, excluding seven who responded insincerely. A total of $207(43.1 \%)$ male students were surveyed and a total of $266(55.4 \%)$ female students were surveyed.

\subsection{Instruments}

1) Perceived Stress: The Perceived Stress Scale(PSS) developed by Cohen and others (1983) was used to figure out stressful experiences[20]. The PSS consisted of 10 questionnaires with a five-point scale and the higher score meant more stress levels. In this study, Cronbach's a corresponded to .85 .

2) Subjective Happiness: The Subjective Happiness Scale(SHS) developed by Lyubomirsky and Lepper(1999) was used to measure happiness[21]. The scale was composed of 4 questionnaires which asked whether a person was happy or unhappy with a seven-point Likert scale. The high score meant more happiness. In this study, Cronbach's a corresponded to .85 .

4) Optimism: The Life Orientation Test-Revised(LOT-R) developed by Scheier, Carver and Bridges(1994) was used to measure optimism[9]. This scale was made up of 10 questionnaires, using the average score of 6 questionnaires excepting 4 false ones. The high score meant more optimism. In this study, Cronbach's a corresponded to 85 .

4) Flow: The flow scale developed by Martin and Jackson(2008) was used to assess it[22]. This scale consisted of 9 questionnaires with a five-point scale. The high score meant more flow. In this study, Cronbach's a corresponded to .82 .

5) Control Variables: Participants' gender(male $=1$, female=2), age, religion(religion=1, non-religion=2) and economic levels (very rich=1, very poor=9) were surveyed.

\subsection{Data Analysis}

The collected data in this study were analyzed with SPSS 20.0. Descriptive statistics analysis was conducted to find out demographic descriptors and Pearson's correlation analysis was 
adopted to find out the correlation among variables. The multiple regression analysis was conducted by controlling the demographic variable in order to find out the independent variable's impact on the dependent variable. The bootstrapping was used to find out the significance of a mediation effect. In this study, the research model of a mediation effect was verified with the use of SPSS Macro presented by Hayes and Preacher[23] to verify an indirect effect of the variable. The number of extracting samples for bootstrapping amounted to 5,000 and a medication effect was verified at a $95 \%$ of confidence interval.

\section{Result}

\subsection{Descriptive Statistics and Correlation among Study Variables}

[Table 1] shows descriptive statistics result and correlation among variables with regard to perceived stress, optimism, flow and subjective happiness. The absolute value of variables' skewness is below .86 and the absolute value of the kurtosis is 1.27 and less.

Firstly, perceived stress has a significantly negative correlation with subjective happiness $(\mathrm{r}=-.58, \mathrm{p}<.001)$, optimism $(\mathrm{r}=-.53, \mathrm{p}<.001)$ and flow $(\mathrm{r}=-.34, \mathrm{p}<.001)$. In other words, higher perceived stress leads to lower levels of subjective happiness, optimism and flow. Optimism is highly correlated with flow $(\mathrm{r}=.43, \mathrm{p}<.001)$ and subjective happiness $(\mathrm{r}=.62, \mathrm{p}<.001)$. In other words, higher optimism contributes to higher flow and subjective happiness.

When it comes to the correlation between descriptive statistics variables and each variable, the gender (perceived stress, $\mathrm{r}=.14, \mathrm{p}<.01$ ), age(perceived stress, $\mathrm{r}=-.12, \mathrm{p}<.01$ ) showed a correlation. And economic level are correlated with perceived stress $(r=.11, p<.05)$, flow $(r=-.12$, $\mathrm{p}<.01)$, and subjective happiness $(\mathrm{r}=-.23, \mathrm{p}<.01)$. In other words, women were more stressed and less felt flow than men. The older you are, the less stress you are under. Affluent family circumstances lead to lower levels of perceived stress, the higer the flow and subjective happines. 
Perceived Stress and Happiness in College Students : On the Mediating Effects of Optimism and Flow

[Table 1] Correlation between Variables and Mean, Standard Deviation

\begin{tabular}{lcccccccc}
\hline \multicolumn{1}{c}{ Variables } & 1 & 2 & 3 & 4 & 5 & 6 & 7 & 8 \\
\hline 1. perceived stress & 1.00 & & & & & & & \\
2. optimism & $-.53^{* * *}$ & 1.00 & & & & & & \\
3. flow & $-.34^{* * *}$ & $.43^{* * *}$ & .1 .00 & & & & & \\
4. subjective happiness & $-.58^{* * *}$ & $.62^{* * *}$ & $.40^{* * *}$ & 1.00 & & & & \\
5. gender & $.14^{* *}$ & .02 & -.01 & -.02 & 1.00 & & & \\
6. age & $-.12^{* *}$ & .06 & .00 &.- .03 & -.41 & 1.00 & & \\
7. religion & -.05 & -.01 & .01 & -.01 & -.09 & .03 & & \\
8. economic level & $.11^{*}$ & $-.15^{* *}$ & $-.12^{* *}$ & $-.23^{* *}$ & -.01 & $.15^{* *}$ & 1.00 & \\
\hline \multicolumn{1}{c}{$\mathrm{M}$} & 2.95 & 3.43 & 3.10 & 4.68 & 1.56 & 22.86 & 1.69 & 4.71 \\
\multicolumn{1}{c}{$\mathrm{SD}$} & .53 & .69 & .65 & 1.14 & .49 & 1.95 & .46 & 1.56 \\
\hline \multicolumn{1}{c}{ skewness } & -.05 & -.09 & -.03 & -.33 & -.25 & .59 & -.86 & .15 \\
\hline kurtosis & .64 & -.23 & .02 & .16 & -1.94 & -.36 & -1.27 & .33 \\
\hline
\end{tabular}

${ }^{*} p<.05, \stackrel{* * *}{p}<.01, \stackrel{* * * *}{p}<.001$.

3.2. The Mediation Effect of Optimism and Flow in the Relations Between Perceived Stress and Subjective Happiness

In this study, a dual mediation analysis was conducted with 4-step multiple regression analysis in order to find out a mediation effect of optimism and flow in the relations between perceived stress and subjective happiness. Gender, age, religion, economic level were controlled. [Table 2] shows the result.

The first step is to find out a mediation effect of optimism and flow in the relations between perceived stress and subjective happiness. Then the overall effect(c) where perceived stress affects subjective happiness is negative $(ß=-.57, \mathrm{p}<.001)$. In other words, In other words, the more stress students are late for, the less subjective happiness they has. In the second step, in terms of the effect of perceived stress on optimism, higher levels of perceived stress have a negative effect on optimism $(\beta=-.53, \mathrm{p}<.001)$. This shows that higher levels of perceived stress contribute to higher levels of optimism. In the third step, under the control of perceived stress and optimism respectively, perceived stress has a negative $\operatorname{effect}(\beta=-.21, p<.001)$ on flow. 
Optimism(first mediation variable) has a positive $\operatorname{effect}(\beta=.30, \mathrm{p}<.001)$ on flow(second mediation variable). In the last step, under the control of perceived stress, optimism and flow, perceived stress still has a negative $\operatorname{effect}(\beta=-.33, \mathrm{p}<.001)$ on subjective happiness. And optimism( $(ß=.39, \mathrm{p}<.001)$ and $\operatorname{flow}(\beta=.09, \mathrm{p}<.01)$ has a positive influence on subjective happiness.

These results show that, when it comes to influence where perceived stress has on subjective happiness, mediation variables such as optimism and flow serve as dual mediations and partial mediations.

[Table 2] Effectiveness Parameters

\begin{tabular}{|c|c|c|c|c|c|c|c|c|}
\hline Step & $\begin{array}{l}\text { Dependent } \\
\text { variable }\end{array}$ & $\begin{array}{c}\text { Independent } \\
\text { variable }\end{array}$ & $B$ & S.E. & $B$ & $t$ & $V I F$ & $R^{2}$ \\
\hline \multirow{5}{*}{1} & \multirow{5}{*}{$\begin{array}{l}\text { su bj e ct i ve } \\
\text { happiness }\end{array}$} & gender & .08 & .10 & .04 & .87 & 1.22 & \multirow{5}{*}{.36} \\
\hline & & age & -.03 & .03 & -.05 & -1.23 & 1.25 & \\
\hline & & religion & -.08 & .09 & -.03 & -.83 & 1.01 & \\
\hline & & economic level & -.12 & .03 & $-.17^{\star \star k x}$ & -4.40 & 1.04 & \\
\hline & & perceived stress & -1.24 & .08 & $-.57^{\star \star * *}$ & -15.10 & 1.04 & \\
\hline \multirow{5}{*}{2} & \multirow{5}{*}{ optimism } & gender & .15 & .06 & .11 & 2.53 & 1.22 & \multirow{5}{*}{.31} \\
\hline & & age & .02 & .02 & .07 & 1.53 & 1.25 & \\
\hline & & religion & -.04 & .06 & -.03 & -.68 & 1.04 & \\
\hline & & economic level & -.05 & .02 & $-.11^{* *}$ & -2.71 & 1.04 & \\
\hline & & perceived stress & -.69 & .05 & $-.53^{* \star *}$ & -13.32 & 1.04 & \\
\hline \multirow{6}{*}{3} & \multirow{6}{*}{ flow } & gender & -.00 & .06 & -.00 & -.02 & 1.24 & \multirow{6}{*}{.22} \\
\hline & & age & .01 & .02 & .03 & .70 & 1.26 & \\
\hline & & religion & -.01 & .06 & -.01 & -.29 & 1.01 & \\
\hline & & economic level & -.02 & .02 & -.06 & -1.34 & 1.06 & \\
\hline & & perceived stress & -.26 & .06 & $-.21^{* \star * *}$ & -4.23 & 1.45 & \\
\hline & & optimism & .29 & .05 & $.30^{\text {*kt }}$ & 6.02 & 1.44 & \\
\hline \multirow{7}{*}{4} & \multirow{7}{*}{$\begin{array}{l}\text { subject ive } \\
\text { happiness }\end{array}$} & gender & .01 & .08 & .01 & -.19 & 1.24 & \multirow{7}{*}{.50} \\
\hline & & age & -.05 & .02 & $-.08^{*}$ & -2.04 & 1.25 & \\
\hline & & religion & -.05 & .08 & -.02 & -.64 & 1.01 & \\
\hline & & economic level & -.09 & .03 & $-.12^{* *}$ & -3.44 & 1.07 & \\
\hline & & perceived stress & -.73 & .09 & $-.33^{* k *}$ & -8.17 & 1.51 & \\
\hline & & optimism & .63 & .07 & $.39^{*+* *}$ & 9.02 & 1.56 & \\
\hline & & flow & .16 & .07 & $.09^{*}$ & 2.38 & 1.27 & \\
\hline
\end{tabular}

${ }^{*} p<.05, \quad p<.01, \quad p<.001$.

[Table 2] shows the result on verifying a mediation effect of optimism and flow where perceived stress among college students influences subjective happiness. The single medium of perceived stress on subjective happiness through optimism(Ind1) and flow(Ind2) was shown to have a single effect of optimism and flow as the low and upper limit do not contain 0 . And a 
single mediation effect where perceived stress affects subjective happiness via optimism and the dual mediation effect as an indirect process where perceived stress has an effect on subjective happiness via optimism and flow were significant. [Fig. 2] illustrates the final model of this study based on these results.

[Table 3] Indirectness Effect

\begin{tabular}{lccccc}
\hline Indirect effect & Effectiveness \\
factor & $\begin{array}{c}\text { Boot } \\
\text { S.E. }\end{array}$ & $\begin{array}{c}\text { Boot. } \\
\text { LLCI }\end{array}$ & $\begin{array}{c}\text { Boot. } \\
\text { ULCI }\end{array}$ \\
\hline $\begin{array}{l}\text { Ind1: perceived stress } \rightarrow \text { optimism } \rightarrow \text { subjective } \\
\text { happiness }\end{array}$ & -.44 & .06 & -.57 & -.31 \\
$\begin{array}{l}\text { Ind2: perceived stress } \rightarrow \text { flow } \rightarrow \text { subjective happiness } \\
\text { Ind3: perceived stress } \rightarrow \text { optimism } \rightarrow \text { flow } \rightarrow \text { subjective }\end{array}$ & -.04 & .02 & -.09 & -.01 \\
$\begin{array}{l}\text { happiness } \\
\text { Indirectness effect }\end{array}$ & -.03 & .02 & -.06 & -.01 \\
\hline
\end{tabular}

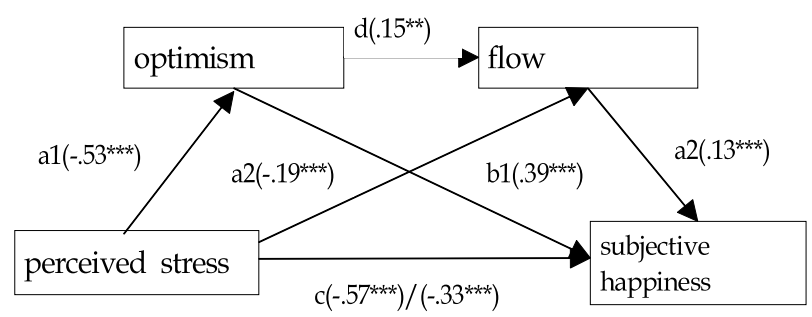

[Fig. 2] Research Model Effect

\section{Conclusion}

Based on the stress-appraisal-coping theory[2], this study is to identify the mediating effects of optimism and flow where perceived stress among college students affects their subjective happiness. The analysis results and discussion are as follows:

Firstly, perceived stress among college students had a direct negative effect on optimism, flow and subjective happiness. In other words, high levels of stress reduced optimism and flow as well as subjective happiness. This result correlated with the previous study which explained that adolescents with low levels of stress showed more optimism than those with higher levels of stress[24][25]. It also supported the advanced study suggesting that optimism with learning was related to higher levels of learning flow[26]. Furthermore, it was in line with the 
preceding research which explained that higher levels of stress caused depression and low well-being[25]. These results showed the need for intervention in assessing their stress levels accurately and interpreting as well as coping with stress.

Secondly, optimism had a mediating effect on the relations between perceived stress and happiness. This meant that optimistic belief in the future played an important psychological role in the relations between perceived stress and subjective happiness. This result correlated with the previous study which suggested that optimism had a positive effect on various areas such as interpersonal relations and psychological adaption as well as well-being[3]. And high levels of optimism led to happier life even under perceived stressful circumstances. Optimistic people were more likely to perceive that they were supported by others even in the same situations and showed positive engagement even under conflict circumstances[27]. It was shown that they handled issues in a cooperative manner[28]. In other words, optimistic people were active in coping with stressful issues and then this attitude was effective in enhancing psychological well-being. Based on this, it is required to reinforce positive alternative resources by helping college students be equipped with positive belief and convictions for the future in order to improve their happiness.

Thirdly, flow had a mediating effect on the relations between perceived stress and happiness. Flow could be an important psychological resource in the relations between perceived stress and happiness. Even though college students were stressful due to academic performances, finding a job and interpersonal relations, being fully immersed in something enough to forget the passage of time and fatigue would make them competent and delightful[14] as well as happier. This shows the need for providing a program and education to help them have experience enough to be involved in it in their daily lives.

Finally, perceived stress had dual and partial mediating effects on happiness after going through optimism and flow. This meant that stressful conditions made college student less optimistic and poor flow made them less happy. The result was in line with the stress-appraisal-coping theory suggested by Lazarus and Folkman. In other words, even in stressful situations, psychological issues could be different based on internal variables. Likewise, it is important for college students to be equipped with positive and optimistic convictions from their mental health perspective. It is also recommended to extend alternative resources in order for students to cope with stress by strengthening their flow.

These results require stress management programs in order to intervene in the mental health for college students. They also suggest that the programs need the factors to enhance optimism for the future and flow. And it is also meaningful in that it revealed psychological resources 
and pathways to cope with stress.

As study variables are measured through self-reporting, this study has its limitation. So it is required to be complemented with various methods such as observation, interview and experimental studies. College students are under stress due to academic performances, employment, interpersonal relation and romantic issues and economic difficulties. With this in mind, it is necessary to figure out the relations with other variables including cognition and the strategy for adjusting emotions. In the future study, it is recommended to develop stress management programs in helping college students shift optimistic convictions and enhance flow, verifying their effectiveness.

\section{Acknowledgement}

This Research was supported by the Tongmyong University Research Grants 2018(2018F060).

\section{Reference}

[1] T. Y. Moon and S. H. Park, A study on the relationship of demographic characteristic to stressor and stress-coping behavior among university students, Journal of Sport and Leisure Studies, (2007), Vol.30, pp.913-925.

[2] R. Lazarus and S. Folkman, Stress, Appraisal, and Coping, New York: Springer, (1984)

[3] E. Y. Kim, I. H. Park, Y. K. Kim, and C. M. Lee, Perceived Stress and Depression in Adolescence: On the Mediating Effects of Optimism and Emotional Regulation, Journal of Learner-Centered Curriculum and Instruction, (2015) Vol.15, No.2, pp.373-388.

[4] M. R. Song, H. Y. Ahn, and E. K. Kim, A study on the correlation between stress, mother-adolescent communication and quality of life in the adolescents, Korean Journal of Child Health Nursing, (2002), Vol.8, pp.141-151.

[5] H. Ayyash-Abdo, Adolescent suicide: An ecological approach, Psychology in the Schools, (2002), Vol.39, pp.459-475.

[6] J. V. Lavigne and J. Faier-Routman, Correlates of psychological adjustment to pediatric physical disorders: A meta-analytic review and comparison of existing models, Journal of Developmental and Behavioral Pediatrics, (1993), Vol.14, pp.117-123.

[7] R. Lazarus and S. Folkman, Stress, appraisal, and coping, New York: Springer, (1984)

[8] A. S. Masten and J. D. Coatsworth, The Development of competence in favorable and unfavorable environments lessons from research on successful children. American Psychologist, (1998), Vol.53, 
pp. $205-220$.

[9] M. F. Scheier, C. S. Carver, and M. W. Bridges, Distinguishing optimism from neuroticimcand trait anxiety, self-mastery, and self-esteem: A re-evaluation of the Life Orientation Test, Journal of Personality and Social Psychology, (1994), Vol.67, pp.1063-1078.

[10] C. Ciro, R. Alessandro, L. Elena, and D. V. Olivia, A. Francesca, and A. R. Mario, Optimism and its impact on mental and physical well-being, Clinical Practice Epidemiology Mental Health, (2010), Vol.6, pp.25-29.

[11] J. A. Choi, M. H. Lee, Y. Kwon, I. C. Choi, and E. S. Choi, Are optimistic people happy or are happy people pptimistic?:A longitudinal analysis for the examination of causal relationship between optimism and happiness, Korean Journal of Social and Personality Psychology, (2016), Vol.30, No.3, pp.95-114.

[12] M. J. Lee and J. A. Choi, The effect of optimism on psychological well-being: Stress coping strategies as a mediating variable, Korean Journal of Counseling, (2013), Vol.14, No.6, pp.3739-3751.

[13] H. J. Lee, Study on the moderating effects of cognitive strategies, optimism in a relationship between stress and depression among teenagers, Journal of Learner-Centered Curriculum and Instruction, (2017), Vol.17, No.12, pp.751-773.

[14] M. Csikszentmihalyi, Flow and the foundations of positive psychology: The collected works of Mihaly Csikszentmihalyi, Dordrecht: Springer, (2014)

[15] M. Csikszentmihalyi, Flow: The classic work on how to achieve happiness, Random House, (2002)

[16] J. LeFervre, Flow and the quality of experience during work and leisure, optimal experience, Cambridge: Cambridge University Press, (1988)

[17] A. Wells, Self-esteem and optimal experience. Optimal experience, Cambridge: Cambridge University Press, (1988)

[18] J. S. Lee and J. H. Lee, An analysis of the structural relationship among teachers' autonomy, optimism, teaching flow, and subjective well-being, The Journal of Korean Teacher Education, (2011), Vol.28 No.1, pp.66-90.

[19] H. I. Cho, The Analysis of relationships between academic optimism, learning flow, academic stress, and academic achievement of high school students, The Korean Journal of Educational Psychology, (2013), Vol.27, No.4, pp.783-803.

[20] S. Cohen, T. Kamarck, \& R. Mermelstein, A global measure of perceived stress, Journal of Health and Social Behavior, (1983), Vol.24, pp.386-396.

[21] S. Lyubomirsky and H. Lepper, A measure of subjective happiness: Preliminary reliability and construct validation, Social Indicators Research, (1999), Vol.46, pp.137-155.

[22] A. J. Martin and S. A. Jackson, Brief approaches to assessing task absorption and enhanced subjective experience: Examining 'short' and 'core' flow in diverse performance domains, Motivation and Emotion, (2008), Vol.32, pp.141-157.

[23] A. F., Hayes and K. J. Preacher, Statistical mediation analysis with a multicategorical independent variable, British Journal of Mathematical and Statistical Psychology, (2014), Vol.67, pp.451-470. 
Perceived Stress and Happiness in College Students : On the Mediating Effects of Optimism and Flow

[24] M H. Gang, J. S. Kwon, and K. O. Oh, Influencing factors of resilience of adolescents according to stress, Stress Management, (2012), Vol.20, No.3, pp.187-198.

[25] J. M. Kim, The moderating effect of optimism and perceived parental empathy in the relation between school-related stress and depression, Korea Youth Research Association, (2014), Vol,21, No.4, pp.203-225.

[26] K. S. Beard, Academic optimism, flow, enabling school structures and life optimism. Leading research in educational administration, New York: Information Age Publishing Inc, (2011)

[27] C. S. Carver, M. F. Scheier, and S. C. Segerstrom, Optimism, Clinical Psychology Review, (2010), Vol.30, pp.879-889.

[28] K. K. Assad, M. B. Donnellan, and R. D. Conger, Optimism: An enduring resource for romantic relationships, Journal of Personality and Social Psychology, (2007), Vol.93, pp.285-297. 